\title{
ABELARDO VILLEGAS 0 EL LÚCIDO ASEDIO SOBRE LA ESQUIVA IDENTIDAD MEXICANA In Memoriam
}

ENRIQUE LUJÁN SALAZAR

Departamento de Letras/Departamento de Filosofia, UAA

Abelardo Villegas, El pensamiento mexicano en el siglo XX. Fondo de Cultura Económica, México, 1993. 251 pp. (Sección: Política y Derecho).

\footnotetext{
C
} Conocí a Abelardo Villegas en 1982 cuando tomaba la clase de Antropología filosófica en la Facultad de Filosofía y Letras de la UNAM. Su gran saber, su curiosidad intelectual aunados a una gran bonhomía hacían de nuestro curso un grato encuentro en el cual el pensamiento discurría dúctil y ágil sobre las teorías más áridas y controversiales sobre la problemática condición humana. Ahora que me he enterado de su reciente fallecimiento presento esta reseña de $E l$. pensamiento mexicano en el siglo $X X$ como un recuerdo cariñoso al maes- tro que infundió en muchas generaciones un gusto peculiar por la indagación filosófica y que nos mostró que el saber, la lucidez y el humor pueden cohabitar aun en las más abstractas disquisiciones sobre la filosofía.

En el amplio marco de las discusiones sobre la identidad mexicana y latinoamericana, el Comité de la Historia de las Ideas en América le encomendó al doctor Villegas una historia del pensamiento mexicano en el siglo xx. Entre la multiplicidad de criterios y modos de investigar esta cuestión nuestro autor abordó la diversidad de materiales e ideas a partir del tema central de México. El conocimiento de nuestro país es uno de los objetivos primordiales y condiciones sine qua non para lograr una búsqueda más acertada de soluciones que den respuesta a nuestras proble-

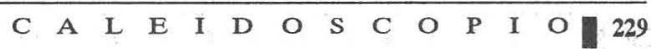


máticas actuales, y así poder elaborar modelos que nos permitan construir un futuro más promisorio para nuestra nación.

El filósofo comienza tratando las relaciones entre el cientificismo, que surgió a finales del siglo XIX como una cosmovisión que impregnó todo el acontecer social, y la Revolución Mexicana, que desató la inconformidad contra el gobierno de Porfirio Díaz. Sostiene que las raíces ideológicas del movimiento armado surgen de la fetichización del positivismo utilizado por el porfiriato. La negación de las libertades políticas, la sujeción social, la hipoteca de los bienes nacionales en manos de los capitales extranjeros y la interpretación de una cierta moral derivada del positivismo fueron las fuentes de inconformidad que fueron gestando los grupos de oposición que encabezaron la Revolución. La pugna comenzó entre 'positivistas' y 'espiritualistas'. El conocimiento cientúfico, al ser considerado como la verdad definitiva y la 'mejor clase' de conocimiento, se convirtió en un nuevo mito que sirvió para justificar la tiranía porfirista bajo el lema de "orden y progreso". Aunado a estas inconformidades, se formaron grupos intelectuales disidentes socialistas que cuestionaron al liberalismo que se impo- nía en todos los ámbitos sociales.

El verdadero rompimiento intelectual con esta posición positivo-científica lo constituyó el movimiento del Ateneo de la Juventud. Un conjunto de pensadores que compartían intereses y principios comunes se opusieron a la ideología dominante del porfiriato. Antonio Caso, Pedro Henríquez Ureña, José Vasconcelos, Carlos González Peña, Alfonso Reyes y Martín Luis Guzmán, entre otros; formaban el núcleo que pretendía abrir la mentalidad mexicana hacia nuevos horizontes. Denuncian el contubernio porfirismo-positivismo, la cerrazón de los pensadores positivistas a considerar otros saberes que no fueran los científicos y la necesidad de impulsar la cultura mexicana. Sus ideas y concepciones del mundo provienen de diferentes fuentes: desde los clásicos griegos hasta los filósofos vitalistas contemporáneos, desde el pensamiento indostánico hasta el pensamiento cristiano. Este bagaje cultural les permitió analizar diferentes problemas de los mexicanos, hacer nuevas propuestas para la vida nacional e impulsar iniciativas concretas para renovar el pensamiento y la educación mexicana.

Continúa el doctor Abelardo presentando con sencillez, pero sin per- 
der profundidad, los problemas nacionales que se presentaron en la década de los veinte: el conflicto entre la Iglesia y el Estado mexicano que da lugar a la ideología y a la guerra cristera; el movimiento fallido del vasconcelismo para encumbrar al Ulises mexicano a la presidencia; el surgimiento del Partido Nacional Revolucionario, impulsado por la visión sagaz de Plutarco Elías Calles; así como del Partido Acción Nacional, fundado por Manuel Gómez Morín, y el movimiento cultural impulsado por el 'Segundo Ateneo' conformado por los Siete Sabios, entre los que sobresalen: Alberto Vázquez del Mercado, Antonio Castro, Lombardo Toledano y Alfonso Caso. Vemos aquí la conformación de un nuevo rostro nacional, el nacimiento de un México con instituciones, el origen de los sindicatos obreros y campesinos y el surgimiento del México presidencialista y unipartidista que pone fin a los gobiernos militares postrevolucionarios.

La ventana que el doctor Villegas nos abre al pasado continúa y da cuenta del surgimiento del grupo de los Contemporáneos y su afán universalista, la necesidad de ir más allá de la circunstancia nacional y de abrir a México al mundo contempo- ráneo; luego indaga cómo la influencia socialista continúa permeando la vida nacional, en la que tiene un lugar destacado la polémica CasoLombardo, la educación socialista y la pintura con influencia marxista.

Un hito importante del texto lo encontramos en el capítulo que aborda el cardenismo. De nuevo, como amo del matiz, nuestro maestro no se inclina por una visión maniquea de este período; ni acepta la etiqueta marxista que Luis Cabrera le endilga al gobiemo de Cárdenas, ni tampoco acepta la interpretación reformista que de esta época nos da Tzvi Medin.

El gobierno de Cárdenas fue muy significativo para el país en diferentes aspectos; en tanto que rompe con el Maximato que había instaurado Calles y recupera los ideales populares de la Revolución Mexicana, no sin modificar e incorporar las ideas de vanguardia para los nuevos problemas que enfrentaba México. Cárdenas inicia una revolución agrícola y obrera, promueve la lucha social dentro de la ley que permita a obreros y campesinos una mejor situación social y económica; defiende la supremacía del Estado por la responsabilidad social que tiene como árbitro y repartidor de la riqueza, "sólo el Estado tiene un interés general y por 
tanto una visión de conjunto". La actuación de Cárdenas no es socialista sino nacionalista, concluye, en este capítulo, nuestro autor.

Las dimensiones internacionales de la solidaridad mexicana se vieron fortalecidas cuando nuestro país aceptó a miles de españoles que salían de su tierra para escapar de la dictadura franquista y preservar así sus valores libertarios. Este acontecimiento histórico marcó una nueva era de relaciones con los peninsulares; comienza la época de relaciones de igualdad con España y para México inicia un encuentro con el pensamiento contemporáneo a través de los intelectuales que transmitieron y alentaron la reflexión sobre nuestra propia circunstancia. Entre los pensadores más destacados estuvieron José Gaos, Joaquín Xirau, Wenceslao Roces, Eugenio Ímaz, José María Gallegos, Eduardo Nicol y Adolfo Sánchez Vázquez, entre otros. Con ellos cambiaría la perspectiva del pensamiento y de la educación superior en México. Familiarizados con los autores clásicos, con el pensamiento alemán -idealismo, marxismo, fenomenología y existencialismo-con el perspectivismo de Ortega y Gasset y con el pensamiento cristiano impulsaron a través de la docencia, la in- vestigación, la creación y la difusión la necesidad de elaborar un pensamiento que diera cuenta de la circunstancia mexicana y de la historia del pensamiento producido en nuestro país. La filosofía ya no será sólo considerada como una cosmovisión subyacente a todo el actuar humano sino que además se convertirá en instrumento para encontrar nuestro mundo y nuestra vida desde una posición histórica determinada. Surge así un movimiento que no solamente buscó la identidad del mexicano, sino que interpretó nuestra realidad con categorías propias, por ejemplo los términos de 'corazón', 'rostro', 'flor y canto' utilizados en La filosofía náhuatl de León Portilla. Surge el grupo Hiperión que trata de dar cuenta de esta identidad. Leopoldo Zea, Emilio Uranga, Jorge Portilla, Ricardo Guerra y Luis Villoro llegan a conclusiones poco alentadoras para definir cuáles son esas características que históricamente ha manifestado la identidad mexicana: no somos más que lo accidental, de aquí la improvisación, el relajo y la exaltación y burla de la muerte. Octavio Paz por su cuenta nos señala en El laberinto de la soledad que lo peculiar del mexicano es la conciencia de ser distintos y ésta nos lleva a la soledad, no 
hemos encontrado la 'forma' que nos exprese cabalmente y nos hemos ocultado tras diferentes máscaras en una charada sin fin. Esta búsqueda de la identidad se extendió al pensamiento latinoamericano y Zea encontró que, si bien coincidíamos en valores con la cultura occidental, nuestros intereses eran diferentes.

El reto para todos estos pensadores y para cualquier mexicano y latinoamericano es afrontar nuestra tradición ambigua, cercenada y discontinua y ser creativos para construir un proyecto propio que integre el pasado y nos lleve al futuro. En este apartado hay una observación que nos indica la posición afirmativa y libertaria de nuestro autor al indicar que no somos malas copias de diferentes proyectos de nación, sino que enfrentados a ciertas circunstancias históricas hemos ido seleccionando y optando por aquellos aspectos teóricos o prácticos que nos han permitido ir resolviendo los problemas que se nos han presentado. De esta manera, debemos asumir creativamente nuestras múltiples dependencias, económicas, políticas, culturales, así como nuestros anhelos de libertad. En esa oscilación histórica fructificará un pensamiento que pueda dar cuenta de quiénes somos y a dónde vamos.
En los siguientes capítulos el doctor Villegas analiza cómo vimos retroceder los ideales revolucionarios, cómo la presión internacional se hizo más fuerte y estaba atenta a lo que pasaría en México después del gobierno de Cárdenas y, a su vez, cómo la derecha se fue consolidando a través del sinarquismo y el crecimiento del Partido Acción Nacional. Las izquierdas fueron esclerotizándose y llegaron a convertirse en cenáculos culturales que impedían un pensamiento libre adaptado a nuestras circunstancias históricas. En este sentido son memorables las críticas que hizo José Revueltas al Partido Comunista Mexicano.

Luego el maestro mexicano se ocupa de dar cuenta del movimiento estudiantil de 1968. Aquí nos encontramos otra vez con la lucidez del pensamiento de Abelardo. Busca más allá de los acontecimientos sangrientos el significado que nos permita valorar esa revolución universitaria. Coincide con diversos intérpretes del movimiento, pero va más allá. Considera que "la ideología del movimiento estudiantil fue plural, fragmentaria, desarticulada, y a veces nada más estuvo implícita". El propósito del movimiento se podría resumir en la tesis que proponía que los institutos 
de educación superior se deberían transformar en barricadas o baluartes desde los cuales se provocara la revolución social. El estudiantado universitario debería convertirse en la vanguardia política del país. Esto conllevaba enfrentar varios problemas: el gobierno atacaba al estudiantado de extranjerizante y sedicioso, los obreros no entendían el discurso marxista-trotkista-maoísta-estudiantil, algunos profesores rechazaron el movimiento, algunos intelectuales como Octavio Paz renunciaron a sus cargos públicos y reconocieron la habilidad política de los estudiantes, pero su plataforma intelectual la consideraron hueca y rígida; por otra parte los estudiantes universitarios y politécnicos tenían una visión diferente de lo que podían alcanzar con su movilización: unos la transformación del país, otros las demandas contempladas en el pliego petitorio y quizá algo más.

El movimiento fue detenido abruptamente. Entre las causas no militares que no permitieron que éste se expandiera, podemos considerar: la falta de apoyo masivo de los obreros y del pueblo en general. Si bien el reparto de la riqueza no se había dado en la medida de lo esperado, sí se había ido consolidando una clase media y los trabajadores y campesinos no se encontraban en la misma situación desesperada que prevalecía a fines del porfiriato. Otra causa que impidió que el movimiento fuera más amplio es que se trataba de un movimiento político y por tanto era parcial en sus demandas y sólo denunciaba el autoritarismo del gobierno y la necesidad de mejorar la educación pero no atendía a otros problemas sociales.

A Luis Echeverría le tocó enfrentar las secuelas del conflicto. Tuvo la habilidad de congraciarse con los líderes estudiantiles y con los grupos intelectuales dándoles puestos en la burocracia política, permitió la liberación de los presos políticos y posibilitó la creación de instituciones educativas vanguardistas como los Colegios de Ciencias y Humanidades y la Universidad Autónoma Metropolitana. Sin embargo, la disidencia o la crítica política no estaba permitida. Ante estas nuevas circunstancias se formaron grupos guerrilleros que perseguían diferentes objetivos. La apertura política sólo se dio por los cauces institucionales. Los presidentes José López PortiIlo, Miguel de la Madrid y Carlos Salinas de Gortari impulsaron reformas que permitieron a diferentes 
partidos políticos acceder a las Cámaras legislativas.

Con este tema sobre las secuelas del conflicto revolucionario de 1968 y señalando esquemáticamente los diferentes problemas económicos, políticos y culturales a los que México se enfrenta, Abelardo Villegas cierra el viaje sobre la historia del pensamiento mexicano no sin hacer una última alusión a la discusión sobre si el día 12 de octubre debemos celebrarlo como un encuentro de dos mundos, en palabras de León Portilla, o como un descubrimiento en el cual somos inventados por los europeos, en palabras de Edmundo O'Gorman, y sólo nos queda el destino aciago de repetir aquella condición a la cual nos ha limitado el occidente. En el fondo de esta discusión y de todo el texto está la búsqueda de autoconocimiento, la capacidad de construcción de proyectos como naciones independientes y el descubri- miento de lo que somos y queremos.

Nos encontramos frente a una obra lúcida, intuitiva e imprescindible para todo estudioso de las ciencias sociales, del arte, de la religión y de la filosofía en el siglo XX en nuestro país. Por otra parte, al destacar los vínculos que existen entre lo universal y lo mexicano y emprender un repaso de las corrientes ideológicas que han predominado, coexistido y pugnado entre sí, nuestro maestro sigue enseñándonos las vías para comprender una etapa decisiva en el desarrollo social, político y cultural de México. Saber quiénes somos y a dónde vamos se constituyen en dos interrogantes básicas para poder construir proyectos de una nación más libre, más justa y más desarrollada. Ahora nosotros tenemos la palabra y la necesidad de seguir colaborando con esta insigne y proteica labor: "todo está en su punto y el de ser mexicanos, en el primero". 
